\title{
Functionalized twistacenes for solid state nonlinear optical materials
}

\author{
Guixia Zhai $^{\mathrm{a}, 1}$, Xinyue $\mathrm{Li}^{\mathrm{b}, 1}$, Pengcheng $\mathrm{Jin}^{\mathrm{a}}$, Sergey Semin ${ }^{\mathrm{c}}$, Jinchong Xiao ${ }^{\mathrm{a}, *}$, Theo Rasing ${ }^{\mathrm{c}}$, \\ Jialiang $\mathrm{Xu}^{\mathrm{b}, * *}$

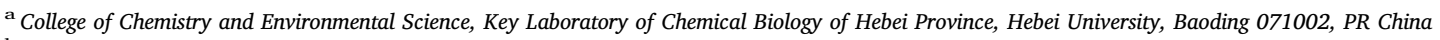 \\ ${ }^{\mathrm{b}}$ School of Chemical Engineering and Technology, Tianjin University, Yaguan Road 135, Tianjin 300350, PR China \\ ${ }^{\mathrm{c}}$ Radboud University, Institute for Molecules and Materials (IMM), Heyendaalseweq 135, 6525 AJ Nijmegen, The Netherlands
}

\section{A R T I C L E I N F O}

\section{Keywords:}

Twisted structure

Single crystal

Acene

Physical property

Nonlinear optical response

\begin{abstract}
A B S T R A C T
A series of twistacenes with different substituents have been synthesized, characterized, and their nonlinear optical properties in the solid state have been explored. It is demonstrated that 2,7-di-tert-butyl- $N, 9,20$-triphenyltetrabenzo[ $a, c, j k, o p]$ pentacen-11-amine crystals having a centrosymmetric $\mathrm{C}_{2}$ /c space group exhibit thirdorder and strong second-order nonlinear optical responses with well-defined polarization dependencies.
\end{abstract}

\section{Introduction}

Highly efficient nonlinear optical (NLO) materials have aroused considerable research interest during the past decades for their wide applications in lasers, data storage, electro-optics, optical limiters, frequency conversion and optical switches [1-3]. Benefiting from their well-defined structural flexibility and functionality, and featuring extended $\pi$-electron delocalizations, organic $\pi$-conjugated compounds have been widely explored as NLO materials [4-6]. Their diverse advantages include fast response, tailor-made structures and tuneable bandgap [7-9]. The NLO properties of these $\pi$-conjugated molecular systems are often interrelated with their intrinsic intramolecular charge transfer (ICT) characteristics $[10,11]$ and symmetry properties [12-16]. In particular, for second-order NLO processes such as second harmonic generation (SHG), a non-centrosymmetric molecular arrangement is in principle required [17].

Polycyclic aromatic hydrocarbons (PAHs) are one of the most thoroughly investigated groups of organic $\pi$-conjugated molecules [18]. Among the various PAHs, twistacene and its derivatives have been the subjects of extensive investigations in recent years, which demonstrate novel synthetic strategies, interesting optoelectronic properties and applications in organic optoelectronic devices [19-28]. The twisted topological structures of twistacenes can not only suppress the $\pi$ stacking interaction to some extent, but also effectively enhance the molecular photo and thermal stability compared with the acenes. For example, the Wudl, Zhang and Xiao groups successively synthesized diverse twistacenes exhibiting strong fluorescence emission in the visible region with tuneable bandgaps [29-42], which have been employed as active ingredients for organic light emitting devices that exhibit fascinating electroluminescence properties. Furthermore, the three-dimensional architecture based on twistacene units forms nanoparticles through self-assembly, resulting in multicolour nanomaterials selectively adhered to the membrane and cytoplasm of HeLa cells [43]. These twistacenes, featuring the extended $\pi$-conjugation as well as the chemical variability and structural diversity, could serve as ideal candidates for NLO materials. However, the NLO properties of twistacene and its derivatives have been relatively unexplored, but are highly valued for broadening their applications in the fields such as photonic devices and NIR bio-imaging. Recently, we found that twistacene derivatives are promising NLO materials by studying their third-order nonlinear optical two-photon absorption (TPA) properties in solution using the Z-scan technique $[44,45]$, where the as-synthesized spindletype molecules exhibited a broadband optical limiting capability that the wavelength could range from $500 \mathrm{~nm}$ to $1000 \mathrm{~nm}$ exposing to femtosecond, picosecond and nanosecond laser pulses. Here, we are more interested in the solid state NLO responses of the twistacenes and their derivatives. Thus, three novel functionalized twistacenes with different suspending subsitutents PTPA/OPTPA/NPTPA have been designed, synthesized and characterized (Scheme 1). Molecule PTPA presented a twisted configuration with the twisted angle of 33.55 determined at C19-C20-C24 and C47-C49-C50. All of them emitted olive fluorescence in dichloromethane. Furthermore, we investigated the

\footnotetext{
* Corresponding author.

*** Corresponding author.

E-mail addresses: jcxiaoicas@163.com (J. Xiao), jialiang.xu@tju.edu.cn (J. Xu).

${ }^{1}$ These authors contributed equally to this work.
} 

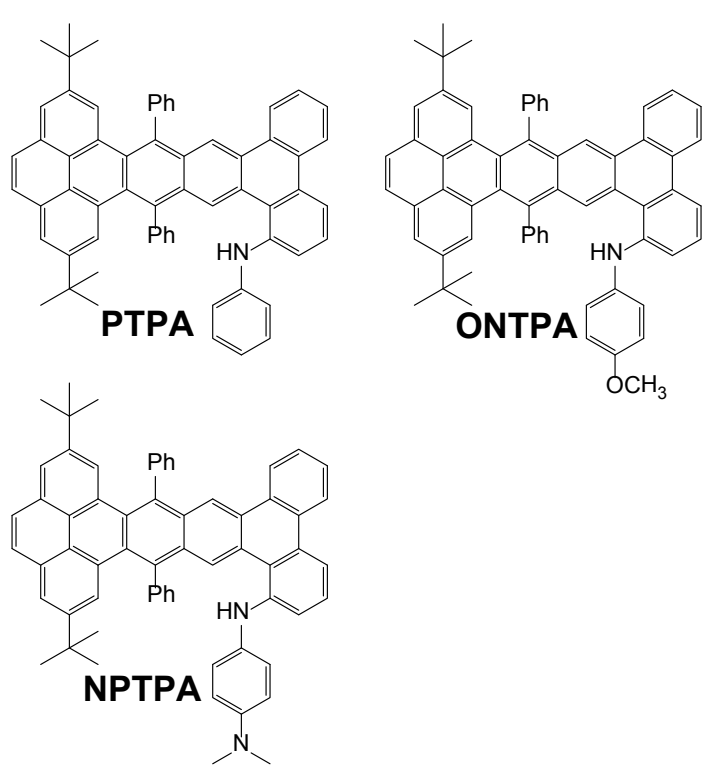

Scheme 1. Molecular structures of PTPA, OPTPA and NPTPA.

solid state second- and third-order NLO behaviors of PTPA crystals.

\section{Experimental}

\subsection{Materials and instruments}

NMR spectra were recorded in deuterated solvents on a $600 \mathrm{MHz}$ Bruker NMR spectrometer. MALDI-TOF mass spectra were obtained on Bruker Biflex III MALDITOF. UV-Vis absorption and PL spectra were measured on a Shimadzu UV-2550 and RF5300PC spectrometers. The solid quantum yields were determined with an integrating sphere on New Fluorolog TCSPC Spectrofluorometer from HORIBA. Thermogravimetric analysis (TGA) was finished with a NETZSCH STA449C under nitrogen by heating the samples from 30 to $800{ }^{\circ} \mathrm{C}$ at a heating rate of $10{ }^{\circ} \mathrm{C} / \mathrm{min}$. Cyclic voltammetry (CV) was carried out in a tetrabutylammonium hexafluorophosphate (TPAPF6, $0.1 \mathrm{~mol} / \mathrm{L}$ ) supported dry dichloromethane at room temperature using a $\mathrm{CHI} 630 \mathrm{~A}$ electrochemical workstation operated at a scanning rate of $50 \mathrm{mV} / \mathrm{s}$. Ferrocene/ferrocenium was used as the internal reference to calibrate the redox potentials.

\subsection{Synthesis procedure}

\subsubsection{1,12-bis(3-bromophenyl)-2,7-di-tert-butyl-9,14-diphenyldibenzo [de, qr]tetracene (3)}

$\mathrm{Pd}\left(\mathrm{PPh}_{3}\right)_{4}$ (40 mg, $\left.0.035 \mathrm{mmol}\right)$ was added to a mixture of compound 1 (362 mg, $0.5 \mathrm{mmol}), 2$-bromophenylboronic acid $(2,251 \mathrm{mg}$, $1.25 \mathrm{mmol})$ and $\mathrm{K}_{2} \mathrm{CO}_{3}(138 \mathrm{mg}, 1 \mathrm{mmol})$ in $\mathrm{THF} / \mathrm{H}_{2} \mathrm{O}(20 \mathrm{~mL}: 10 \mathrm{~mL})$ solution. The reaction solution was degassed and then stirred at $85{ }^{\circ} \mathrm{C}$ for $16 \mathrm{~h}$. After cooling to room temperature, THF was removed under reduced. The as-obtained solution was extracted with dichloromethane (30 $\mathrm{mL})$ for three times. The collected organic phase was dried over $\mathrm{Na}_{2} \mathrm{SO}_{4}$ and evaporated. The residue was purified with silica gel column chromatography using petroleum ether and dichloromethane $(\mathrm{v} / \mathrm{v}$, 100:1) to afford 3 as a yellow solid (202 mg, 46\%). FT-IR (KBr): 3053, 2953, 2907, 2863, 1601, 1451, 1023, 883, 757, 731, $694 \mathrm{~cm}^{-1} .{ }^{1} \mathrm{H}$ NMR (600 MHz, $\left.\mathrm{CDCl}_{3}, 298 \mathrm{~K}\right): \delta=8.20(\mathrm{~d}, J=7.8 \mathrm{~Hz}, 2 \mathrm{H}), 8.14$ (s, 2H), 7.97-7.93 (m, 2H), 7.87-7.85 (m, 4H), 7.78-7.76 (m, 2H), 7.58 (d, $J=7.8 \mathrm{~Hz}, 2 \mathrm{H}), 7.44\left(\mathrm{t},{ }^{1} J=7.8 \mathrm{~Hz},{ }^{2} J=7.2 \mathrm{~Hz}, 2 \mathrm{H}\right), 7.33(\mathrm{t}, 2 \mathrm{H})$, $7.22(\mathrm{~d}, J=7.8 \mathrm{~Hz}, 2 \mathrm{H}), 7.06-6.98(\mathrm{~m}, 6 \mathrm{H}), 1.13(\mathrm{~s}, 18 \mathrm{H}) .{ }^{13} \mathrm{C} \mathrm{NMR}$ $\left(150 \mathrm{MHz}, \mathrm{CDCl}_{3}, 298 \mathrm{~K}\right): \delta=147.3,142.0,141.7,137.6,136.2$, $133.8,132.5,131.8,131.6,130.8,130.5,130.3$, 129.7, 129.6, 129.2,
128.8, 128.4, 127.8, 127.7, 126.9, 126.7, 123.9, 122.3, 34.8, 31.4. MS (MALDI-TOF): calc. for $\mathrm{C}_{56} \mathrm{H}_{44} \mathrm{Br}_{2}$ : $[\mathrm{m} / \mathrm{z}]$ 876.2, found: $[\mathrm{m} / \mathrm{z}] \mathrm{876.5}$.

\subsubsection{2,7-di-tert-butyl-N,9,20-triphenyltetrabenzo[a,c,jk,op]pentacen-11- amine (PTPA)}

A mixture of 3 (131 mg, $0.15 \mathrm{mmol}$ ), aniline (21 mg, $0.23 \mathrm{mmol}$ ), $\mathrm{Pd}(\mathrm{OAc})_{2}(17 \mathrm{mg}, 0.08 \mathrm{mmol})$, tricyclohexylphosphine ( $\mathrm{PCy}_{3}, 21 \mathrm{mg}$, $0.08 \mathrm{mmol}), \mathrm{KO}^{t} \mathrm{Bu}(170 \mathrm{mg}, 1.5 \mathrm{mmol})$ in toluene $(20 \mathrm{~mL})$ was stirred and heated at $110{ }^{\circ} \mathrm{C}$ for $48 \mathrm{~h}$ under nitrogen atmosphere. After cooling to room temperature, toluene was removed and then water was added. The aqueous phase was extracted with dichloromethane for three times. The formed organics was dried with $\mathrm{Na}_{2} \mathrm{SO}_{4}$ and the solvent was evaporated. The residue was purified by column chromatography (silica gel) with petroleum ether/dichloromethane $(\mathrm{v} / \mathrm{v}, 25: 1)$ to afford a yellow solid (40 mg, 33\%). FT-IR (KBr): 3422, 3056, 2953, 2905, 2863, 1596, 1500, 1444, 1303, 884, 749, $691 \mathrm{~cm}^{-1} .{ }^{1} \mathrm{H}$ NMR $(600 \mathrm{MHz}$, $\left.\mathrm{CDCl}_{3}, 298 \mathrm{~K}\right): \delta=9.90(\mathrm{~s}, 1 \mathrm{H}), 9.01(\mathrm{~s}, 1 \mathrm{H}), 8.48(\mathrm{~d}, J=7.8 \mathrm{~Hz}, 1 \mathrm{H})$, 8.24-8.19 (m, 3H), $8.13(\mathrm{~s}, 1 \mathrm{H}), 7.84(\mathrm{~s}, 3 \mathrm{H}), 7.81(\mathrm{~s}, 1 \mathrm{H}), 7.75(\mathrm{~d}$, $J=7.8 \mathrm{~Hz}, 2 \mathrm{H}), 7.68\left(\mathrm{t},{ }^{1} J=7.8 \mathrm{~Hz},{ }^{2} J=7.2 \mathrm{~Hz}, 2 \mathrm{H}\right), 7.60-7.43(\mathrm{~m}$, $7 \mathrm{H}), 7.23\left(\mathrm{t},{ }^{1} J=7.8 \mathrm{~Hz},{ }^{2} J=7.2 \mathrm{~Hz}, 2 \mathrm{H}\right), 7.14\left(\mathrm{t},{ }^{1} J=7.8 \mathrm{~Hz}\right.$, $\left.{ }^{2} J=7.2 \mathrm{~Hz}, 2 \mathrm{H}\right), 7.06\left(\mathrm{t},{ }^{1} J=7.8 \mathrm{~Hz},{ }^{2} J=7.2 \mathrm{~Hz}, 1 \mathrm{H}\right), 6.88(\mathrm{t}$, $\left.{ }^{1} J=7.2 \mathrm{~Hz},{ }^{2} J=6.6 \mathrm{~Hz}, 1 \mathrm{H}\right), 6.69(\mathrm{~d}, J=8.4 \mathrm{~Hz}, 2 \mathrm{H}), 5.80(\mathrm{~s}, 1 \mathrm{H})$, 1.14 (s, 9H), 1.07 (s, 9H). ${ }^{13} \mathrm{C}$ NMR (150 MHz, $\left.\mathrm{CDCl}_{3}, 298 \mathrm{~K}\right)$ : $\delta=147.33,147.27,142.72,142.69,142.1,141.5,136.2,135.8,133.0$, $132.7,131.8,130.7,130.62,130.60,130.55,130.4,130.3,130.0$, $129.9,129.8,129.7,129.4,129.2,129.1,128.6,127.92,127.87$, $127.78,127.71,127.69,127.65,127.61,127.3,127.0,126.9,124.0$, $123.9,123.5,122.4,122.34,122.26,121.1,120.6,119.3,118.0,117.3$, $34.75,34.71,31.4,31.3$. MS (MALDI-TOF): calc. for $\mathrm{C}_{62} \mathrm{H}_{49} \mathrm{~N}$ : $[\mathrm{m} / \mathrm{z}]$ 807.4, found: $[\mathrm{m} / \mathrm{z}] \mathrm{807.3}$.

\subsubsection{2,7-di-tert-butyl-N-(4-methoxyphenyl)-9,20-diphenyltetrabenzo [a,c,jk,op] pentacen-11-amine (OPTPA)}

A mixture of 3 (127 mg, $0.15 \mathrm{mmol})$, 4-anisidine $(28 \mathrm{mg}$, $0.23 \mathrm{mmol}), \mathrm{Pd}(\mathrm{OAc})_{2}(17 \mathrm{mg}, 0.08 \mathrm{mmol})$, tricyclohexylphosphine $\left(\mathrm{PCy}_{3}, 21 \mathrm{mg}, 0.08 \mathrm{mmol}\right), \mathrm{KO}^{t} \mathrm{Bu}(168 \mathrm{mg}, 1.5 \mathrm{mmol})$ in toluene $(20 \mathrm{~mL})$ was stirred and heated at $110{ }^{\circ} \mathrm{C}$ for $48 \mathrm{~h}$ under nitrogen atmosphere. After cooling to room temperature, toluene was removed and then brine was added. The aqueous phase was extracted with dichloromethane for three times. The formed organics was dried with $\mathrm{Na}_{2} \mathrm{SO}_{4}$ and the solvent was evaporated. The residue was purified by column chromatography (silica gel) with petroleum ether/dichloromethane (v/v, 4:1) to afford a yellow solid (48 mg, 38\%). FT-IR (KBr): 3429, 3054, 2949, 2902, 1512, 1233, 878, $748 \mathrm{~cm}^{-1} .{ }^{1} \mathrm{H}$ NMR $\left(600 \mathrm{MHz}, \mathrm{CDCl}_{3}, 298 \mathrm{~K}\right): \delta=9.85(\mathrm{~s}, 1 \mathrm{H}), 9.01(\mathrm{~s}, 1 \mathrm{H}), 8.47$ (d, $J=8.4 \mathrm{~Hz}, 1 \mathrm{H}), 8.23$ (t, $2 \mathrm{H}), 8.15(\mathrm{~s}, 1 \mathrm{H}), 8.09$ (d, $J=7.8 \mathrm{~Hz}, 1 \mathrm{H})$, $7.84(\mathrm{~s}, 3 \mathrm{H}), 7.82(\mathrm{~s}, 1 \mathrm{H}), 7.75(\mathrm{~d}, J=7.2 \mathrm{~Hz}, 2 \mathrm{H}), 7.68\left(\mathrm{t},{ }^{1} J=7.8 \mathrm{~Hz}\right.$, $\left.{ }^{2} J=7.2 \mathrm{~Hz}, 2 \mathrm{H}\right), 9.60-7.48(\mathrm{~m}, 5 \mathrm{H}), 7.40\left(\mathrm{t},{ }^{1} J=8.4 \mathrm{~Hz},{ }^{2} J=7.8 \mathrm{~Hz}\right.$, $1 \mathrm{H}), 7.30(\mathrm{t}, J=7.8 \mathrm{~Hz}, 2 \mathrm{H}), 7.23(\mathrm{~d}, J=7.8 \mathrm{~Hz}, 1 \mathrm{H}), 7.16(\mathrm{t}$, $\left.{ }^{1} J=7.8 \mathrm{~Hz},{ }^{2} J=7.2 \mathrm{~Hz}, 1 \mathrm{H}\right), 6.77(\mathrm{~d}, J=8.4 \mathrm{~Hz}, 2 \mathrm{H}), 6.70(\mathrm{~d}$, $J=8.4 \mathrm{~Hz}, 2 \mathrm{H}), 5.85$ (s, 1H), 3.81 (s, 3H), 1.13 (s, 9H), 1.08 (s, 9H). ${ }^{13} \mathrm{C}$ NMR (150 MHz, $\left.\mathrm{CDCl}_{3}, 298 \mathrm{~K}\right): \delta=155.3,147.5,147.4,143.7$, 143.0, 142.5, 136.2, 136.0, 135.8, 133.0, 132.8, 132.1, 131.0, 130.72, $130.70,130.65,130.5,130.48,130.0,129.9,129.8,129.6,129.4$, $128.8,128.1,128.02$, 128.0, 127.9, 127.86, 127.76, 127.7, 127.5, $127.1,127.0,124.14,124.12,124.09,123.6,123.58,122.5,122.4$, $122.1,121.3,120.8,116.9,115.7,114.7,100.1,55.8,34.89,34.87$, 31.52, 31.47. MS (MALDI-TOF): calc. for $\mathrm{C}_{63} \mathrm{H}_{51} \mathrm{NO}$ : $[\mathrm{m} / \mathrm{z}]$ 837.4, found: $[\mathrm{m} / \mathrm{z}] \mathrm{835.6}$.

\subsection{4. $N^{1}$-(2,7-di-tert-butyl-9,20-diphenyltetrabenzo[a,c,jk,op]pentacen- 11-yl)- $N^{4}, N^{4}$-dimethylbenzene-1,4-diamine (NPTPA)}

A mixture of $3(201 \mathrm{mg}, 0.23 \mathrm{mmol}), N, N$-dimethyl-1,4-phenylenediamine $(6,47 \mathrm{mg}, 0.34 \mathrm{mmol}), \mathrm{Pd}(\mathrm{OAc})_{2}(26 \mathrm{mg}, 0.12 \mathrm{mmol})$, tricyclohexylphosphine $\left(\mathrm{PCy}_{3}, 32 \mathrm{mg}, 0.12 \mathrm{mmol}\right.$ ), $\mathrm{KO}{ }^{\mathrm{t}} \mathrm{Bu}$ (336 mg, $2.3 \mathrm{mmol}$ ) in toluene $(20 \mathrm{~mL})$ was stirred and refluxed for $48 \mathrm{~h}$ under 
nitrogen atmosphere. After cooling to room temperature, toluene was removed and then water was added. The aqueous phase was extracted with dichloromethane $(30 \mathrm{~mL})$ for three times. The organics was dried over $\mathrm{Na}_{2} \mathrm{SO}_{4}$ and the solvent was evaporated under reduced pressure. The residue was purified by column chromatography (silica gel) with petroleum ether/dichloromethane ( $\mathrm{v} / \mathrm{v}, 4: 1)$ to afford a yellow solid (22 mg, 11\%). FT-IR (KBr): 3435, 3051, 2956, 2926, 2857, 1604, 1514, 1444, 1359, 883, 757, $699 \mathrm{~cm}^{-1} .{ }^{1} \mathrm{H}$ NMR (600 MHz, $\left.\mathrm{CDCl}_{3}, 298 \mathrm{~K}\right)$ : $\delta=8.68(\mathrm{~d}, J=7.2 \mathrm{~Hz}, 1 \mathrm{H}), 8.57(\mathrm{~s}, 1 \mathrm{H}), 8.48(\mathrm{~d}, J=7.8 \mathrm{~Hz}, 1 \mathrm{H})$, $8.17(\mathrm{~d}, J=6.6 \mathrm{~Hz}, 1 \mathrm{H}), 8.10$ (d, $J=7.2 \mathrm{~Hz}, 1 \mathrm{H}), 7.97$ (d, $J=1.2 \mathrm{~Hz}$, $1 \mathrm{H}), 7.84-7.65(\mathrm{~m}, 9 \mathrm{H}), 7.56\left(\mathrm{t},{ }^{1} J=7.8 \mathrm{~Hz},{ }^{2} J=7.2 \mathrm{~Hz}, 1 \mathrm{H}\right)$, 7.47-7.32 (m, 7H), 7.19 (s, 2H), 6.70 (s, 2H), 6.59 (s, 2H), 2.84 (s, 6H), 1.16 (s, 9H), 1.00 (s, 9H). ${ }^{13} \mathrm{C}$ NMR (150 MHz, $\left.\mathrm{CDCl}_{3}, 298 \mathrm{~K}\right)$ : $\delta=147.3,146.5,143.5,142.1,141.2,136.9,134.4,133.9,133.3$, 132.8, 132.2, 132.1, 130.32, 130.29, 130.1, 129.8, 129.6, 128.6, 128.5, 128.4, 127.7, 127.6, 127.5, 127.3, 127.1, 127.0, 126.8, 126.74, 126.66, 125.7, 125.4, 124.9, 124.0, 123.7, 122.1, 121.9, 121.8, 120.3, 113.7, 113.1, 109.1, 100.0, 34.8, 34.5, 31.5, 31.3, 29.7. MS (MALDI-TOF): calc. for $\mathrm{C}_{64} \mathrm{H}_{54} \mathrm{~N}_{2}$ : $[\mathrm{m} / \mathrm{z}]$ 850.4, found: $[\mathrm{m} / \mathrm{z}]$ 848.4.

\section{Results and discussion}

\subsection{Synthesis}

Scheme 2 summarizes the synthesis of the target compounds PTPA, OPTPA and NPTPA. The intermediate 11,12-bis(2-bromophenyl)-2,7di-tert-butyl-9,14-diphenyldibenzo[de,qr]tetracene(3) was obtained in $46 \%$ yield via a classical Suzuki-coupling reaction between 11,12-dibromo-2,7-di-tert-butyl-9,14-diphenyldibenzo[de,qr] tetracene (1) [39] and the commercially available 2-bromophenylboronic acid (2). The end-capping seven-heteroring fused arene $\mathbf{5}$ are expected to be formed when compound $\mathbf{3}$ was treated with aniline through the Pd-catalyzed Buchwald-Hartwig coupling. However, detailed ${ }^{1} \mathrm{H}$ and ${ }^{13} \mathrm{C}$ NMR together with MALDI-TOF MS spectroscopic characterizations (Fig. S3S14) suggest that the six-membered ring fused twistacene PTPA was formed instead. Other than aniline, 4-anisidine and $N, N$-dimethyl-1,4phenylenediamine have been also used to react with $\mathbf{3}$ under similar conditions, and the reactions also afforded corresponding six-membered ring fused compounds OPTPA and NPTPA. The resulting<smiles></smiles>
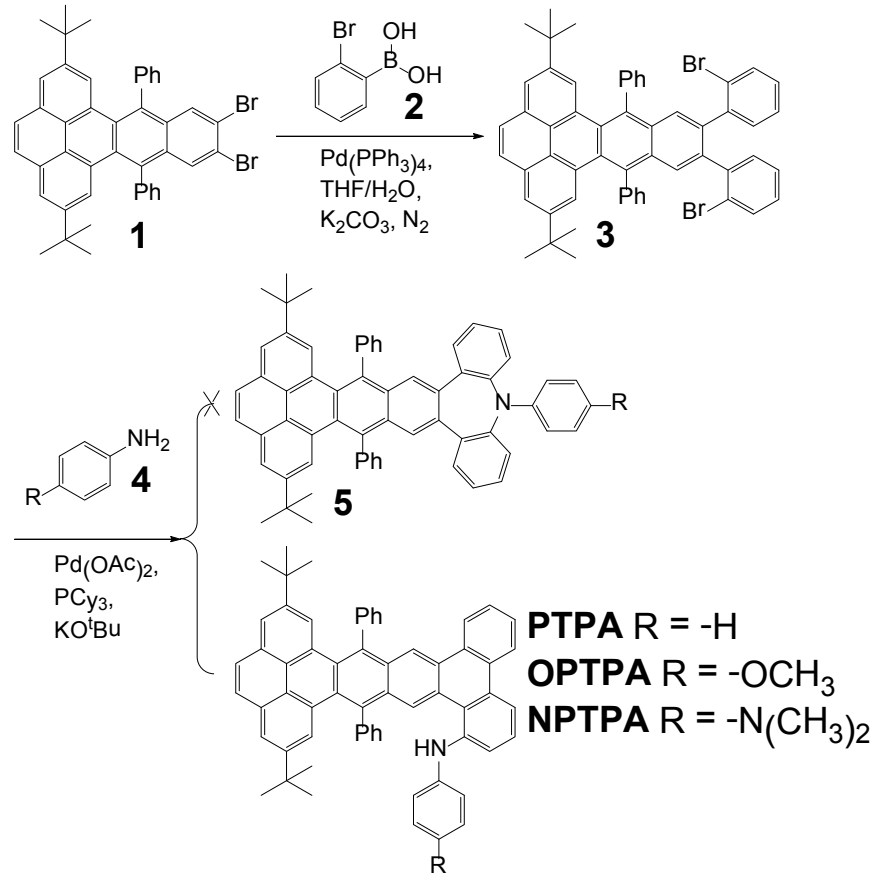

Scheme 2. Synthetic pathway for PTPA, OPTPA and NPTPA.

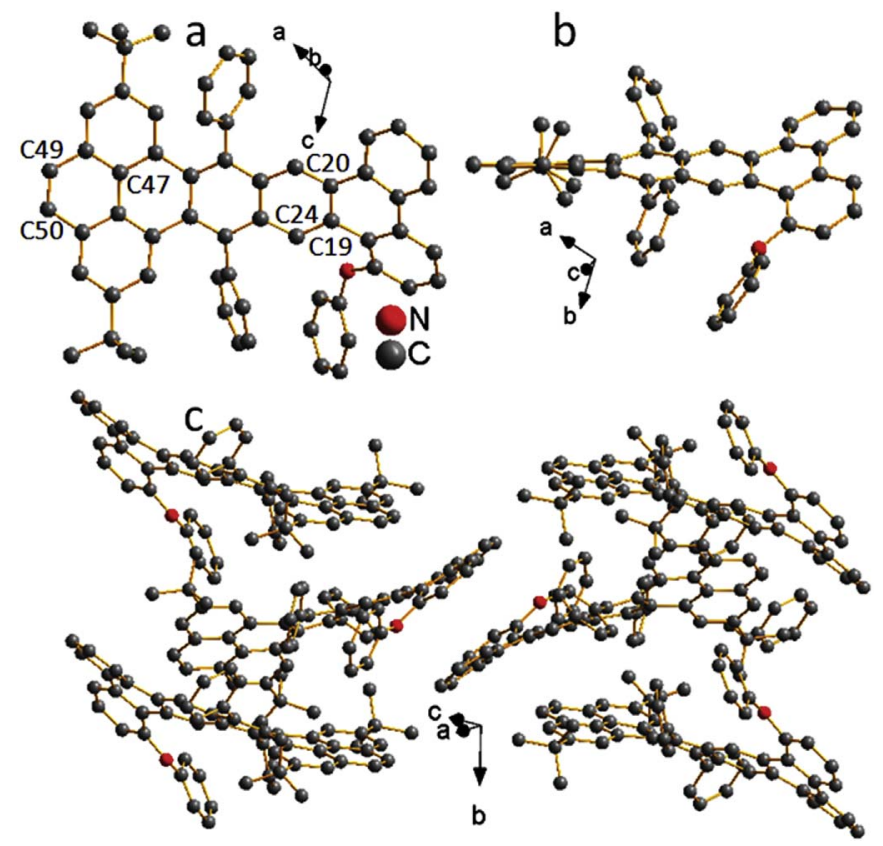

Fig. 1. (a) Single crystal X-ray structure of PTPA, (b) side view and (c) its packing model. Hydrogen atoms are omited for clarity.

compounds are readily soluble in common organic solvents such as toluene, 1,2-dichlorobenzene (ODCB), dichloromethane and chloroform. All of them exhibited high thermal stability as suggested by thermogravimetric analysis (TGA) with about $5 \%$ weight loss occurring at $460{ }^{\circ} \mathrm{C}, 455{ }^{\circ} \mathrm{C}$ and $415{ }^{\circ} \mathrm{C}$, respectively (Fig. S1).

\subsection{Single crystal}

To further clarify the formation of the six-membered ring fused twistacenes instead of the end-capping seven-heteroring fused twistacenes, we attempted to solve the crystal structures of the products. Single crystals of the aniline functionalized product have been obtained for the single-crystal X-ray analysis by slowly evaporation of its solution in a mixture solvent of dichloromethane and methanol. It is suggested that six-membered ring fused twistacenes PTPA was indeed formed (Fig. 1 and Table S1). PTPA crystalizes in a monoclinic unit cell with a space group of $\mathrm{C}_{2} / \mathrm{c}$ and unit cell dimensions $a=34.0909(6) \AA$, $b=10.0929(1) \AA, c=30.5775(6) \AA, \alpha=90^{\circ}, \beta=123.594(3)^{\circ}$, $\gamma=90^{\circ}$ (CCDC number: 1571274). It forms a highly twisted structure, where the end-capping pyrene unit and the adjacent naphthalene moiety are not coplanar because of the steric effect between the benzo moieties and lateral phenyl groups. The twisted angle determined at C19-C20-C24 and C47-C49-C50 is about $33.55^{\circ}$ (Fig. 1a and 1b). More interestingly, the phenylamino group was suspended on the parent twistacene. As shown in Fig. 1c, PTPA presented a slipped one-dimensional motif with an anti-configuration. The mismatch arrangement also suggested poor electronic coupling between adjacent molecules.

\subsection{Optical and electrochemical properties}

The linear UV-vis absorption and fluorescence spectra of the asformed compounds were measured in diluted dichloromethane solution (Fig. 2 and Table S2). PTPA and OPTPA displayed a similar absorption spectrum with the absorption peaks at $462 \mathrm{~nm}, 409 \mathrm{~nm}, 372 \mathrm{~nm}$ and $355 \mathrm{~nm}$. When phenyl or 4-methoxyphenyl substituents were replaced by the 4-(dimethylamino)phenyl group, the resulted molecule NPTPA features a broad low-energy absorption band of 433-471 nm and slightly red-shift bands at $385 \mathrm{~nm}$ and $367 \mathrm{~nm}$. When excited at $370 \mathrm{~nm}$, all the compounds emitted strong green fluorescence centered 


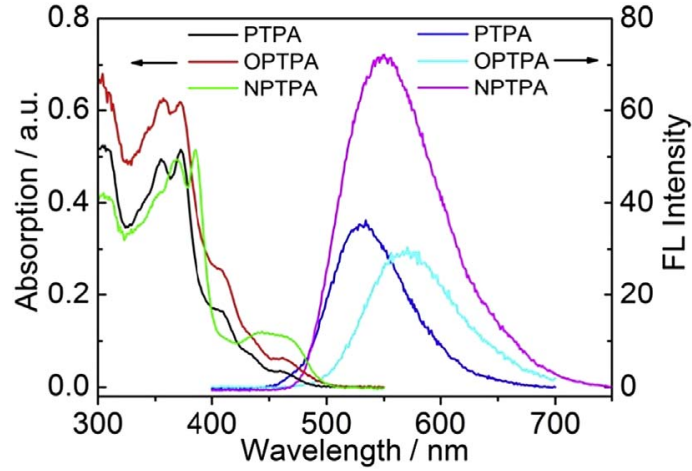

Fig. 2. UV-vis absorption and fluorescence spectra of compounds PTPA, OPTPA, NPTPA in dichloromethane $\left(1.0 \times 10^{-5} \mathrm{M}\right)$.

at $532 \mathrm{~nm}$ for PTPA, $571 \mathrm{~nm}$ for OPTPA and $548 \mathrm{~nm}$ for NPTPA, respectively. The quantum yields $\left(\Phi_{\mathrm{f}}\right)$ were determined to be 0.08 for PTPA, 0.04 for OPTPA, and 0.16 for NPTPA, respectively, with 9,10diphenylanthracene $\left(\Phi_{\mathrm{f}}=0.95\right.$ in ethanol) as a standard [46]. The absolute fluorescence quantum yield in the solid state was $0.1 \%$ for PTPA, $0.06 \%$ for OPTPA and $0.27 \%$ for NPTPA, as determined with an integrating sphere. In addition, the fluorescence times $\left(\tau_{\mathrm{s}}\right)$ were measured to be $2.3 \mathrm{~ns}$ for PTPA, $4.2 \mathrm{~ns}$ for OPTPA and $9.7 \mathrm{~ns}$ for NPTPA (Fig. S2 and Table S2). Based on the equations $\mathrm{K}_{\mathrm{r}}=\Phi_{\mathrm{f}} / \tau_{\mathrm{s}}$ and $\mathrm{K}_{\mathrm{nr}}=(1-$ $\left.\Phi_{\mathrm{f}}\right) / \tau_{\mathrm{s}}$, the radiative rate constant $\left(\mathrm{k}_{\mathrm{r}}\right)$ and nonradiative rate constant $\left(\mathrm{k}_{\mathrm{nr}}\right)$ are $0.35 \times 10^{8} \mathrm{~s}^{-1}, 4.04 \times 10^{8} \mathrm{~s}^{-1}$ for PTPA, $0.10 \times 10^{8} \mathrm{~s}^{-1}$, $2.30 \times 10^{8} \mathrm{~s}^{-1}$ for OPTPA, and $0.16 \times 10^{8} \mathrm{~s}^{-1}, 0.87 \times 10^{8} \mathrm{~s}^{-1}$ for NPTPA, respectively.

The Electrochemical properties of the as-prepared compounds were investigated to evaluate the redox behaviors (Fig. 3 and Table S2). PTPA showed two reversible anionic redox processes with peak potentials at $0.49 \mathrm{~V}$ and $0.77 \mathrm{~V}$ against $\mathrm{Fc} / \mathrm{Fc}^{+}$, corresponding to the oxidation of the amine unit and parent backbone moiety, respectively. When the pendent phenyl group in PTPA were replaced by 4-methoxyphenyl or 4-dimethylaminophenyl group, the as-obtained compounds OPTPA and NPTPA showed similar voltammograms with the oxidation peaks at $0.25 \mathrm{~V}, 0.62 \mathrm{~V}, 0.86 \mathrm{~V}$ and $0.18 \mathrm{~V}, 0.56 \mathrm{~V}, 0.95 \mathrm{~V}$, respectively. This might be ascribed to the oxidation of the amine groups, the suspended methoxy/dimethylamino untis and the acene skeleton. The first oxidation peaks of OPTPA and NPTPA were significantly negatively shifted compared with that of PTPA, suggesting that the suspended substituents affect the electrochemical behavior to a great extent. On the basis of the first oxidation potentials, the highest occupied molecular orbital (HOMO) energy levels were calculated to be $-5.29 \mathrm{eV}$ for PTPA, $-5.05 \mathrm{eV}$ for OPTPA and $-4.98 \mathrm{eV}$ for NPTPA, respectively. The highest HOMO energy level of NPTPA led to the relative unstability under air environment in comparison to the other two analogues.

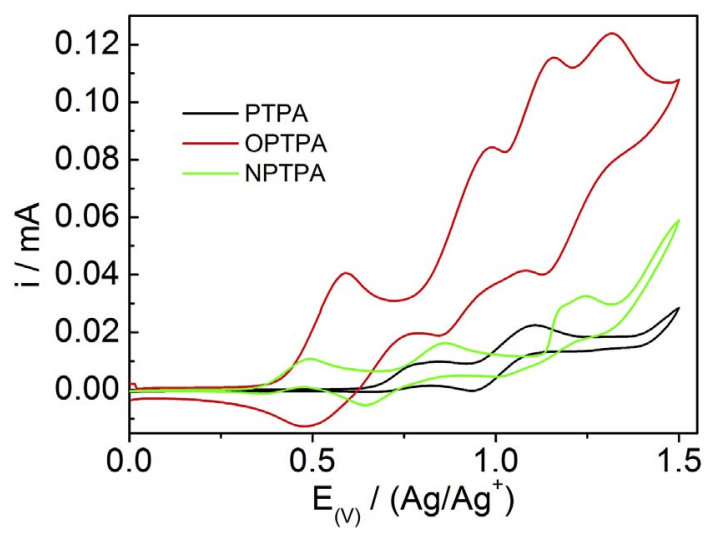

Fig. 3. Cyclic voltammograms of compounds PTPA, OPTPA and NPTPA
Accordingly, the LUMO energy levels are determined to be $-2.74 \mathrm{eV}$ for PTPA (2.55 eV), $-2.57 \mathrm{eV}$ for OPTPA $(2.48 \mathrm{eV})$ and $-2.48 \mathrm{eV}$ for NPTPA $(2.50 \mathrm{eV})$, respectively, based on the oxidation peaks and the band gaps derived from the UV-vis absorption spectra.

\subsection{Nonlinear optical properties}

The nonlinear optical properties of the as-formed PTPA single crystals have been studied using a home-built laser scanning microscope with a pump of femtosecond near-infrared (NIR) laser (wavelength tunable from 730 to $980 \mathrm{~nm}, 120 \mathrm{fs}, 82 \mathrm{MHz}$ ), in a reflection geometry with the incidence and detection angles both at $45^{\circ}$ [13-15]. From the spectrum registered from the PTPA single crystal pumped at $950 \mathrm{~nm}$, one can clearly notice a strong fluorescence response peaked at about $535 \mathrm{~nm}$ (Fig. 4a). This signal resembles the normal fluorescence emission (Fig. 2), but is clearly a nonlinear upconversion two-photon excited fluorescence (TPF) process, given the pump wavelength at $950 \mathrm{~nm}$. Meanwhile a sharp and strong peak at $475 \mathrm{~nm}$ was observed and should be attributed to the second-order nonlinear optical SHG. The scanned image by detecting this SHG signal at $475 \mathrm{~nm}$ shows a clear outline of the rod-like crystal (inset of Fig. 4a), demonstrating that the SHG response originates indeed from the PTPA crystal. The signal intensities of SHG and TPF scale quadratically as function of the power of the pump (Fig. 4b), indicating the intrinsic two-photon nature of both NLO processes. Furthermore, the various spectra taken from the same spot of the PTPA crystal by changing the wavelength of the pump further confirm the different nature of the NLO processes by their wavelength dependencies (Fig. 4c). The SHG peak position shifts, being always half the wavelength of the pump. In contrast, the TPF stays at the same peak position, with various intensities as the pump wavelength changes. The intensities of both SHG and TPF as function of the wavelength show a clear enhancement effect (inset of Fig. 4c) in resonance with the linear absorption bands (Fig. 2). The observed intensity of both NLO responses as function of the polarization angle of the incident pump demonstrated well-defined angular dependencies. The intensity of TPF demonstrated a dipolar plot in the polarization dependence with the highest responses when the incident pump was $p$ polarized (polarization angle $\theta=0^{\circ}$ and $180^{\circ}$ ). In contrast, the polarization dependence of SHG demonstrated a quadrupole plot, reaching the maximum intensity when the polarization angle was about $45^{\circ}$, $135^{\circ}, 225^{\circ}$, and $315^{\circ}$. The polarization ratio, $\rho=\left(I_{\max }-I_{\min }\right) /\left(I_{\max }+\right.$ $\left.I_{\text {min }}\right)$, was determined to be $0.95 \pm 0.05$ and $0.97 \pm 0.01$ for the SHG and TPF of the PTPA crystal, respectively. The very high polarization ratios of both NLO responses reveal the intrinsic well-defined structure. The efficiency of the second-order nonlinearity of the PTPA crystal was evaluated by measuring its SHG intensity in comparison with that of the Y-cut quartz under the same measurement conditions. The results suggested that the PTPA crystals have a relative value of $5 \%$ to that of the Y-cut quartz at $800 \mathrm{~nm}$. The observation of such a relatively strong SHG signal from the PTPA crystal is quite surprising considering its centrosymmetric monoclinic space group of $\mathrm{C}_{2} / \mathrm{c}$. Similar observations of strong SHG in centrosymmetric crystal phases have been recently reported from the $\mathrm{Zn}(\mathrm{II})$ complex $\left(\mathrm{C}_{2} / \mathrm{c}\right)$ [47] and potassium dihydrogen phosphate (KDP, $\mathrm{P}_{1} / \mathrm{c}$ ) crystals [48]. In these studies, it is argued that either the residual non-centrosymmetry [47] or the symmetry-breaking in the twin-crystal lattice in conjunction with tight confinement of the light field by the microcrystal structure [48] could be the origins of the observed strong SHG from these "centrosymmetric" crystals. Such attributions might also apply to the observation of strong SHG from the centrosymmetric PTPA crystal with the same $\mathrm{C}_{2} / \mathrm{c}$ space group in this case. The observation of SHG from the bulk "centrosymmetric" solid-state materials of twistacenes might open the opportunities for advanced photonic applications of these novel materials. 

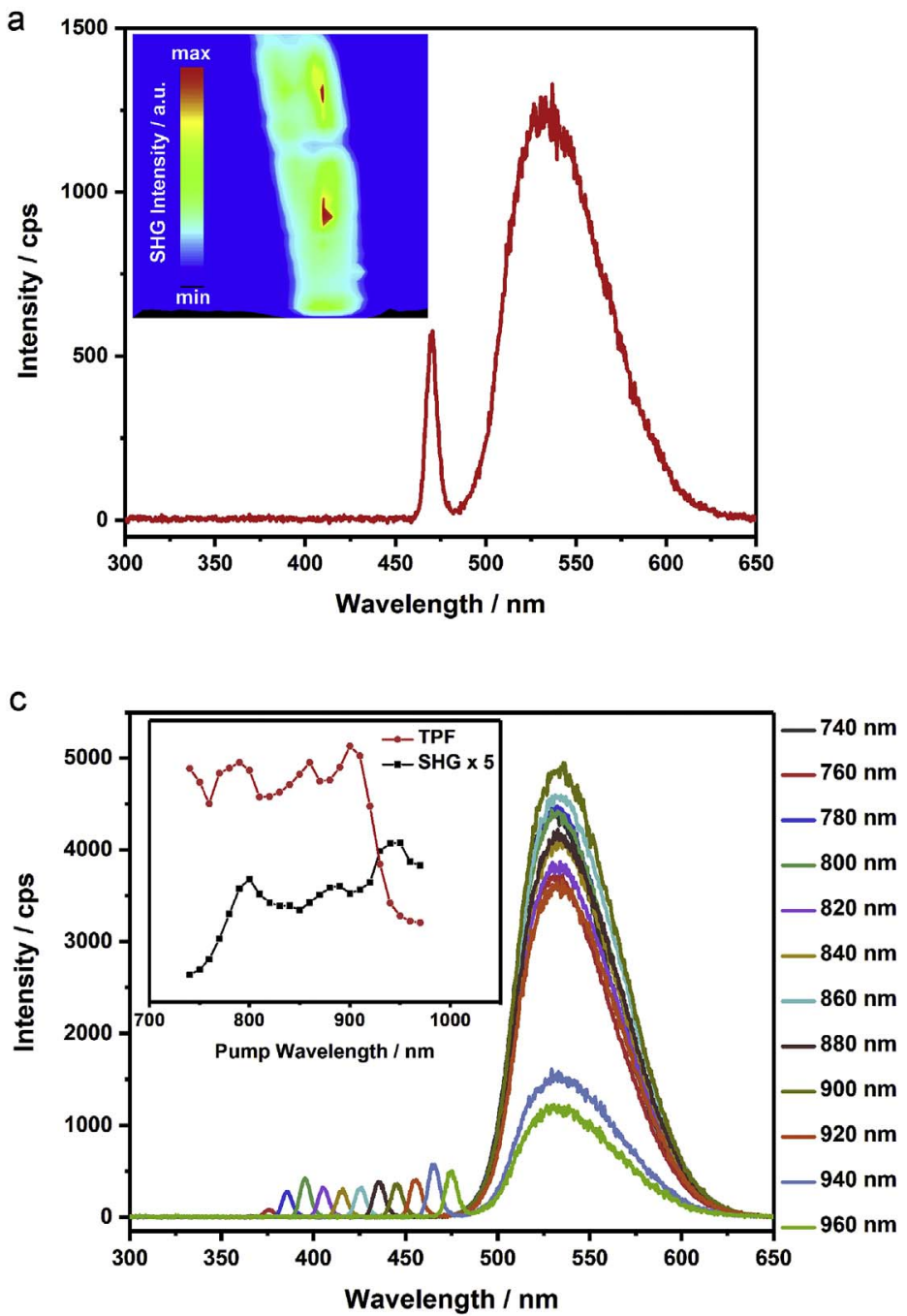

b
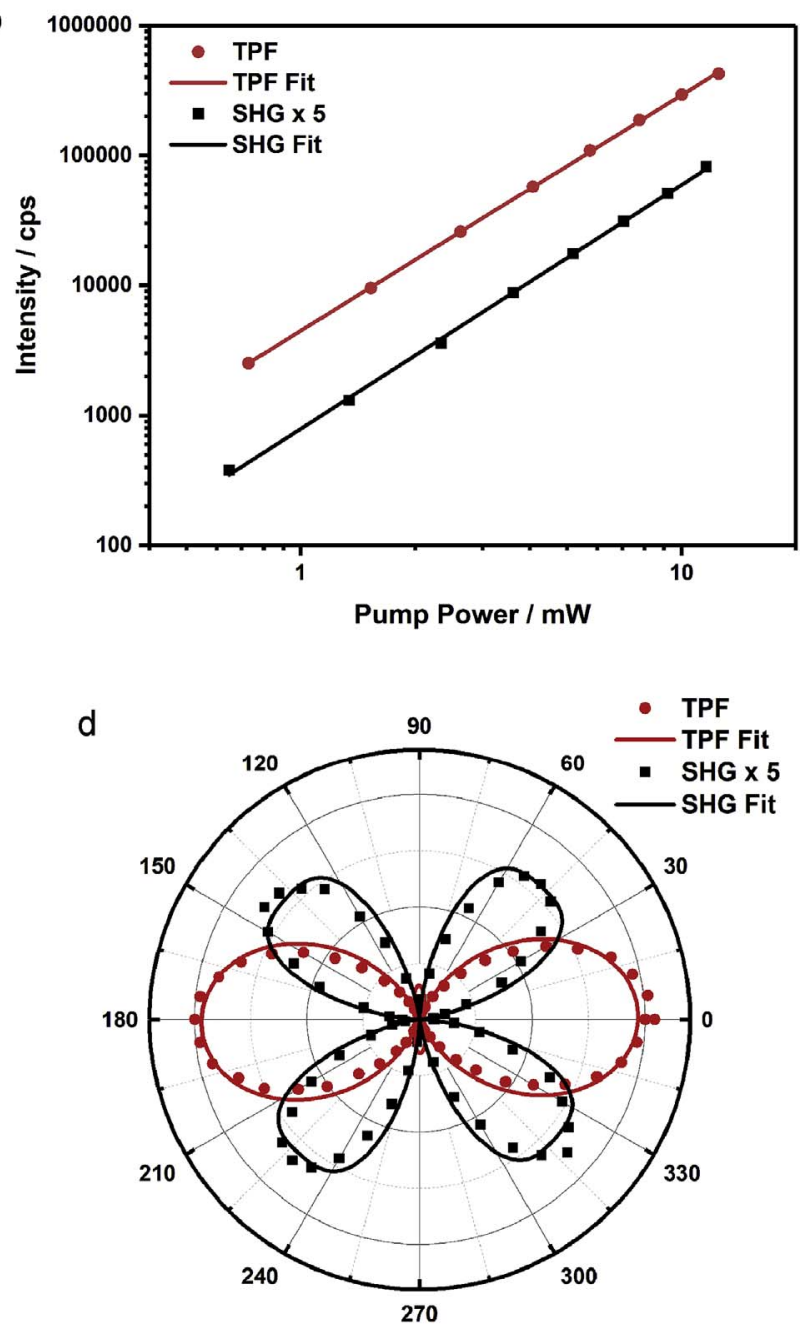

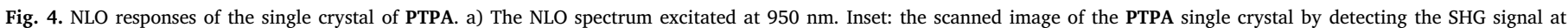

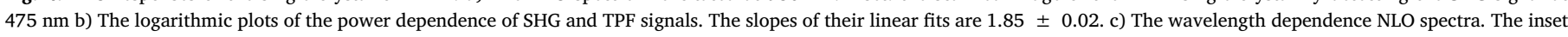

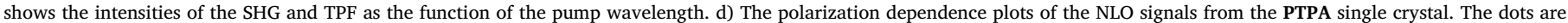
experimental data and the solid lines are the $\cos ^{4} \theta$ and $\cos ^{2} \theta$ fits for SHG and TPF, respectively. The PTPA single crystal is vertically aligned relative to the plane of incidence.

\section{Conclusions}

In summary, we have synthesized a family of functionalized twistacenes modified with pyrene and phenanthrene units at the terminal. The compound PTPA forms well-defined crystals with a monoclinic $\mathrm{C}_{2}$ / c unit cell. The crystal exhibits not only strong third-order optical nonlinearity, but also strong SHG, despite of the centrosymmtric crystal structure. Although more detailed structural investigations and extra knowledge for the molecular crystals are necessary to understand the origin of this phenomenon, the observed strong NLO responses along with their very high polarization ratios promise wide applications of twistacene materials in the fields such as photonic devices and NIR bioimaging.

\section{Acknowledgements}

The financial supports from the National Natural Science Foundation of China (21442010, 21672051, 21773168 and 51503143), the Natural Science Foundation of Hebei Province for Distinguished Young Scholar (B2017201072, Cultivation Project, B2015201183), the Natural Science Foundation of Hebei University (2015JQY02) and the Tianjin Natural Science Foundation (16JCQNJC05000) are greatly appreciated. Part of this work was supported by the Netherlands
Organization of Scientific Research (NWO) with the Veni Grant (68047-437), and the Royal Netherlands Academy of Arts and Sciences (KNAW) with the China-Exchange Program (530-4CDP02). A. Toonen is acknowledged for technical assistances.

\section{Appendix A. Supplementary data}

Supplementary data related to this article can be found at http://dx. doi.org/10.1016/j.dyepig.2017.12.009.

\section{References}

[1] Xu J, Boyd RW. Fischer GL nonlinear optical materials. Reference module in materials science and materials engineering. Elsevier B.V; 2016. p. 6237-44.

[2] Gieseking RL, Mukhopadhyay S, Risko C, Marder SR, Brédas JL. 25th Anniversary article: design of polymethine dyes for all-optical switching applications: guidance from theoretical and computational studies. Adv Mater 2014;26:68-84.

[3] Xu J, Semin S, Rasing T, Rowan AE. Organized chromophoric assemblies for nonlinear optical materials: towards (sub)wavelength scale architectures. Small 2015;11:1113-29.

[4] Alías S, Andreu R, Blesa MJ, Franco S, Garín J, Gragera A, et al. Synthesis, structure, and optical properties of 1,4-dithiafulvene-based nonlinear optic-phores. J Org Chem 2007;72:6440-6.

[5] Coe BJ, Fielden J, Foxon SP, Harris JA, Helliwell M, Brunschwig BS, et al. Diquat derivatives: highly active, two-dimensional nonlinear optical chromophores with potential redox switchability. J Am Chem Soc 2010;132:10498-512. 
[6] Marco AB, Burrezo PM, Mosteo L, Franco S, Garín J, Orduna J, et al. Polarization, second-order nonlinear optical properties and electrochromism in 4H-pyranylidene chromophores with a quinoid/aromatic thiophene ring bridge. RSC Adv 2015;5:231-42.

[7] Sun C, Lv S, Liu Y, Liao Q, Zhang H, Fu H, et al. Benzoindolic squaraine dyes with a large two-photon absorption cross-section. J Mater Chem C 2017;5:1224-30.

[8] Zhao M, Liu K, Zhang Y, Wang Q, Li Z, Song Y, et al. Singlet fission induced giant optical limiting responses of pentacene derivatives. Mater Horiz 2015;2:619-24.

[9] De Torres M, Semin S, Razdolski I, Xu J, Elemans JAAW, Rasing T, et al. Extended pi-conjugated ruthenium zinc-porphyrin complexes with enhanced nonlinear-optical properties. Chem Commun 2015;51:2855-8.

[10] Li Y, Liu T, Liu H, Tian M, Li Y. Self-assembly of intramolecular charge-transfer compounds into functional molecular systems. Acc Chem Res 2014;47:1186-98.

[11] Wang C, Fan C, Yuan C, Yang G, Li X, Ju C, et al. Third- and high-order nonlinear optical properties of an intramolecular charge-transfer compound. RSC Adv 2017;7:4825-9.

[12] Shen YR. Harmonic generation. The principle of nonlinear optics. New Jersey: John Wiley \& Sons. Inc; 2003.

[13] Duan Y, Ju C, Yang G, Fron E, Coutino-Gonzalez E, Semin S, et al. Aggregation induced enhancement of linear and nonlinear optical emission from a hexaphenylene derivative. Adv Funct Mater 2016;26:8968-77.

[14] Xu J, Semin S, Niedzialek D, Kouwer PHJ, Fron E, Coutino E, et al. Self-assembled organic microfibers for nonlinear optics. Adv Mater 2013;25:2084-9.

[15] Xu J, Semin S, Cremers J, Wang L, Savoini M, Fron E, et al. Controlling microsized polymorphic architectures with distinct linear and nonlinear optical properties. Adv Opt Mater 2015;3:948-56.

[16] Wang C, Zhang T, Lin W. Rational synthesis of noncentrosymmetric metal-organic frameworks for second-order nonlinear optics. Chem Rev 2012;112:1084-104.

[17] Marder SR, Sohn JE, Stucky GD. Materials for nonlinear optics: chemical perspectives. Boston, MA, USA: American Chemical Society; 1991.

[18] Clar E. Polycyclic hydrocarbons. London: Academic Press; 1964

[19] Pascal Jr. RA. Twisted acenes. Chem Rev 2006;106:4809-19.

[20] Walters RS, Kraml CM, Byrne N, Ho DM, Qin Q, Coughlin FJ, et al. Configurationally stable longitudinally twisted polycyclic aromatic compounds. J Am Chem Soc 2008;130:16435-41.

[21] Rodríguez-Lojo D, Pérez D, Peña D, Guitián E. Large phenyl-substituted acenes by cycloaddition reactions of the 2,6-naphthodiyne synthon. Chem Commun 2015;51:5418-20.

[22] Alonso JM, Díaz-Álvarez AE, Criado A, Pérez D, Peña D, Guitián E. [16] Cloverphene: a clover-shaped cata-condensed nanographene with sixteen fused benzene rings. Angew Chem Int Ed 2012;51:173-7.

[23] Xu L, Zhu H, Long G, Zhao J, Li D, Ganguly R, et al. 4-Diphenylamino-phenyl substitued pyrazine: nonlinear optical switching by protonation. J Mater Chem C 2015;3:9191-6.

[24] Yan D, Jones W, Fan C, Wei M, Evans DG. Organic microbelt array based on hydrogen-bond architecture showing polarized fluorescence and two-photon emission. J Mater Chem C 2013;1:4138-45.

[25] Jia J, Li Y, Wang W, Luo C, Han L, Li Y, et al. New quinacridone derivatives: structure-function relationship exploration to enhance third-order nonlinear optical responses. Dyes Pigments 2017;146:251-62.

[26] Xu L, Zhang Q. Recent progress on intramolecular charge-transfer compounds as photoelectric active materials. Sci China Mater 2017;60:1093-101.

[27] Li J, Zhang Q. Linearly fused azaacenes: novel approaches and new applications beyond field-effect transistors (FETs). ACS Appl Mater Interfaces 2015;7:28049-62.

[28] Yan D, Yang H, Meng Q, Lin H, Wei M. Two-component molecular materials of 2,5diphenyloxazole exhibiting tunable ultraviolet/blue polarized emission, pump-enhanced luminescence, and mechanochromic response. Adv Funct Mater
2014;24:587-94.

[29] Duong HM, Bendikov M, Steiger D, Zhang Q, Sonmez G, Yamada J, et al. Efficient synthesis of a novel, twisted and stable, electroluminescent "Twistacene". Org Lett 2003;5:4433-6.

[30] Xu Q, Duong HM, Wudl F, Yang Y. Efficient single-layer "twistacene"-doped polymer white light-emitting diodes. Appl Phys Lett 2004;85:3357-9.

[31] Li J, Zhang Q. Mono- and oligocyclic aromatic ynes and diynes as building blocks to approach larger acenes, heteroacenes, and twistacenes. Synlett 2013;24:686-96.

[32] Xiao J, Duong HM, Liu Y, Shi W, Ji L, Li G, et al. Synthesis and structure characterization of a stable nonatwistacene. Angew Chem Int Ed 2012;51:6094-8.

[33] Xiao J, Malliakas CD, Liu Y, Zhou F, Li G, Su H, et al. "Clean Reaction" strategy to approach a stable, green heptatwistacene containing a single terminal pyrene unit. Chem Asian J 2012;7:672-5.

[34] Xiao J, Liu S, Liu Y, Ji L, Liu X, Zhang H, et al. Synthesis, structure, and physical properties of 5,7,14,16-tetraphenyl-8:9,12:13-bisbenzo-hexatwistacene. Chem Asian J 2012;7:561-4.

[35] Xiao J, Divayama Y, Zhang Q, Doung HM, Zhang H, Boey F, et al. Synthesis, structure, and optoelectronic properties of a new twistacene 1,2,3,4,6,13-hexaphenyl-7:8,11:12-bisbenzo-pentacene. J Mater Chem 2010;20:8167-70.

[36] Li J, Chen S, Wang Z, Zhang Q. Pyrene-fused acenes and azaacenes: synthesis and applications. Chem Rec 2016;16:1518-30.

[37] Li J, Zhao Y, Lu J, Li G, Zhang J, Zhao Y, et al. Double [42] cycloaddition reaction to approach a large acene with even-number linearly fused benzene rings: 6,9,16,19tetraphenyl-1.20,4.5,10.11,14.15-tetrabenzooctatwistacene. J Org Chem 2015;80:109-13.

[38] Liu Z, Xiao J, Fu Q, Feng H, Zhang X, Ren T, et al. Synthesis and physical properties of the conjugated dendrons bearing twisted acenes used in solution processing of organic light-emitting diodes. ACS Appl Mater Interfaces 2013;5:11136-41.

[39] Lv B, Shen X, Xiao J, Duan J, Wang X, Yi Y. Synthesis, single crystal, and physical properties of asymmetrical thiophene/selenophene-fused twistacenes. Chem Asian J 2015;10:2677-82.

[40] Xiao J, Liu Z, Zhang X, Wu W, Ren T, Lv B, et al. Substituent effects in twisted dibenzotetracene derivatives: blue emitting materials for organic light-emitting diodes. Dyes Pigments 2015;112:176-82.

[41] Liu Z, Wang W, Xu W, Chen H, Zhang X, Ren T, et al. Synthesis, characterization and photocurrent behavior of asymmetrical heterotwistacenes. Dyes Pigments 2015;115:143-8.

[42] Lv B, Xiao J, Zhou J, Zhang X, Duan J, Su W, et al. Synthesis, crystal analyses, physical properties, and electroluminescent behavior of unsymmetrical heterotwistacenes. ACS Appl Mater Interfaces 2016;8:18998-9003.

[43] Zhang X, Li S, Liu Z, Wang S, Xiao J. Self-assembled multicolor nanoparticles based on functionalized twistacene dendrimer for cell fluorescent imaging. NPG Asia Mater 2015;7:e230.

[44] Wu X, Xiao J, Sun R, Jin T, Yang J, Shi G, et al. Spindle-type conjugated compounds containing twistacene unit: synthesis and ultrafast broadband reverse saturable absorption. Adv Opt Mater 2016;5:1600712.

[45] Chen S, Xiao J, Zhang X, Shen X, Liu X, Shen F, et al. Effect of the mismatch structure on crystal packing, physical properties and third-order nonlinearity of unsymmetrical twistacenes. Dyes Pigments 2016;134:9-18.

[46] Xiao J, Xiao X, Zhao Y, Wu B, Liu Z, Zhang X, et al. Synthesis, physical properties and self-assembly behavior of azole-fused pyrene derivatives. Nanoscale 2013;5:5420-5.

[47] Nalla V, Medishetty R, Wang Y, Bai ZZ, Sun HD, Wei J, et al. Second harmonic generation from the 'centrosymmetric' crystals. Iucrj 2015;2:317-21.

[48] Ren Y, Zhao X, Hagley EW, Deng L. Ambient-condition growth of high-pressure phase centrosymmetric crystalline KDP microstructures for optical second harmonic generation. Sci Adv 2016;2:e1600404. 